\title{
Sensitivity of water stress in a two-layered sandy grassland soil to variations in groundwater depth and soil hydraulic parameters
}

\section{Rezaei et al.}

Correspondence to: M. Rezaei (meisam.rezaei@ugent.be; meisam.rezaei@ vito.be; meisam.rezaei1@ gmail.com)

The copyright of individual parts of the supplement might differ from the CC-BY 3.0 licence. 


\section{Sensitivity of water stress in a two-layered sandy grassland soil to variations in groundwater depth and soil hydraulic parameters}

\section{Rezaei et al.}

Correspondence to: M. Rezaei (meisam.rezaei@ugent.be; meisam.rezaei@ vito.be; meisam.rezaei1@ gmail.com)

The copyright of individual parts of the supplement might differ from the CC-BY 3.0 licence. 
Supplementary material:

Sensitivity of water stress in a two-layered sandy grassland soil to variations in groundwater depth and soil hydraulic parameters

\section{Sensitivity analysis}

\subsection{Effect of the Groundwater Level (GWL) on Soil Water Content and Water Stress}

A manual sensitivity analysis of the bottom boundary conditions was conducted by applying various conditions. A free drainage and various constant head conditions were imposed by setting a zero pressure head value at the GWL ranging from 120 to $150 \mathrm{~cm}(5 \mathrm{~cm}$ interval) below the soil surface. The effects of these bottom boundary conditions on soil water stress and water content prediction were evaluated for both calibration and validation periods (2012 and 2013).

\subsection{Effect of the GWL on Soil Water Content and Water Stress Predictions}

Figure S1 shows the effects of free drainage and different constant head conditions on water content estimations made using the uncalibrated hydrological model. In the free drainage condition, soil-water content was generally underestimated, especially at deeper observation nodes. The results further show that a constant head boundary condition yields a much better agreement between the model and the observations due to wetter conditions in the lower part of the profile. The constant head condition showing the smallest difference between observations and simulations was in agreement with average groundwater depth observations in 2012 and 2013 (-140 and $-135 \mathrm{~cm}$ respectively) at the location of the sensor (2012: RMSE $=0.018, \mathrm{C}_{\mathrm{e}}=0.27$, and $\mathrm{r}^{2}=0.48 ; 2013$ : $\mathrm{RMSE}=0.024, \mathrm{C}_{\mathrm{e}}=0.26$ and $\mathrm{r}^{2}=0.43$ ). Decreasing the groundwater depth to $-120 \mathrm{~cm}$ overestimated the soil-water content, especially at the three deepest observation nodes. On the contrary, soil water stress was overestimated in free drainage condition, which means that the plant is exposed to water stress most of the time of growing season. While there is almost no water stress predicted in constant head condition with GWL below $135 \mathrm{~cm}$ (Fig. S2). Obviously, results shows constant head boundary condition leads to higher calculated root water uptake as compare as free drainage condition. The results clearly show the great importance of the bottom boundary condition in estimating soil-water content and soil water stress in the soil profile, even for groundwater depths well 
1 below $120 \mathrm{~cm}$ depth and sandy soils. The effect of the boundary condition may well exceed

2 the impact of uncertain hydraulic parameters in a parameter optimization. Despite of Carrera-

3 Hernández et al. (2012) finding, which stated correctly choosing adequate boundary

4 conditions is the first step toward accurately estimation water content and flux across the

5 water table using hydrological model; Result shows, in optimizing the hydraulic model

6 parameters, the effect of the boundary conditions should therefore be assessed simultaneously

7 and then the appropriate boundary conditions should be chosen in term of root water uptake

8 and soil water content.

9
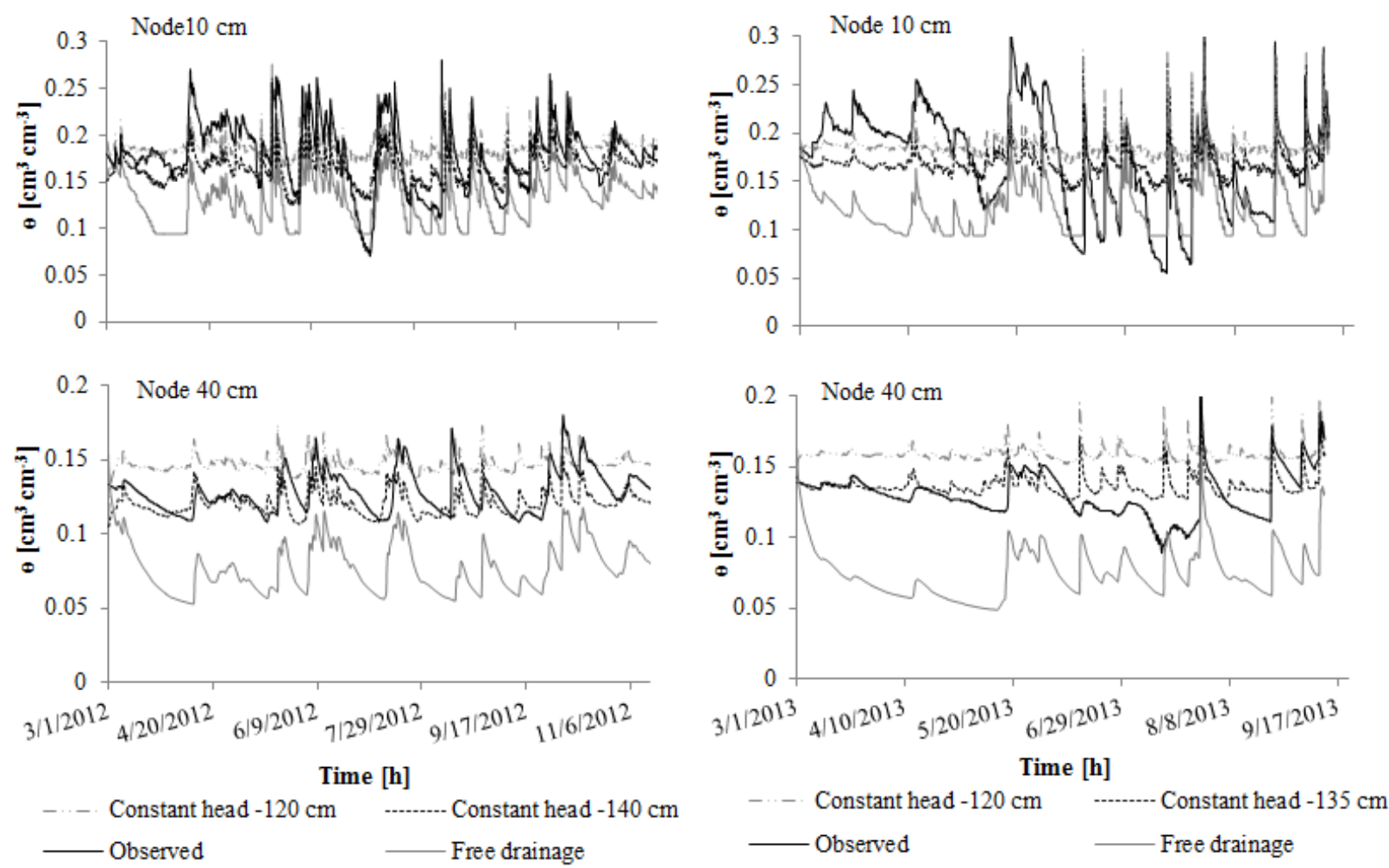

Figure. S1: Water content estimations at 10 and $40 \mathrm{~cm}$ depths using the uncalibrated model for free drainage and different constant head bottom boundary conditions at the soil moisture sensor location. 

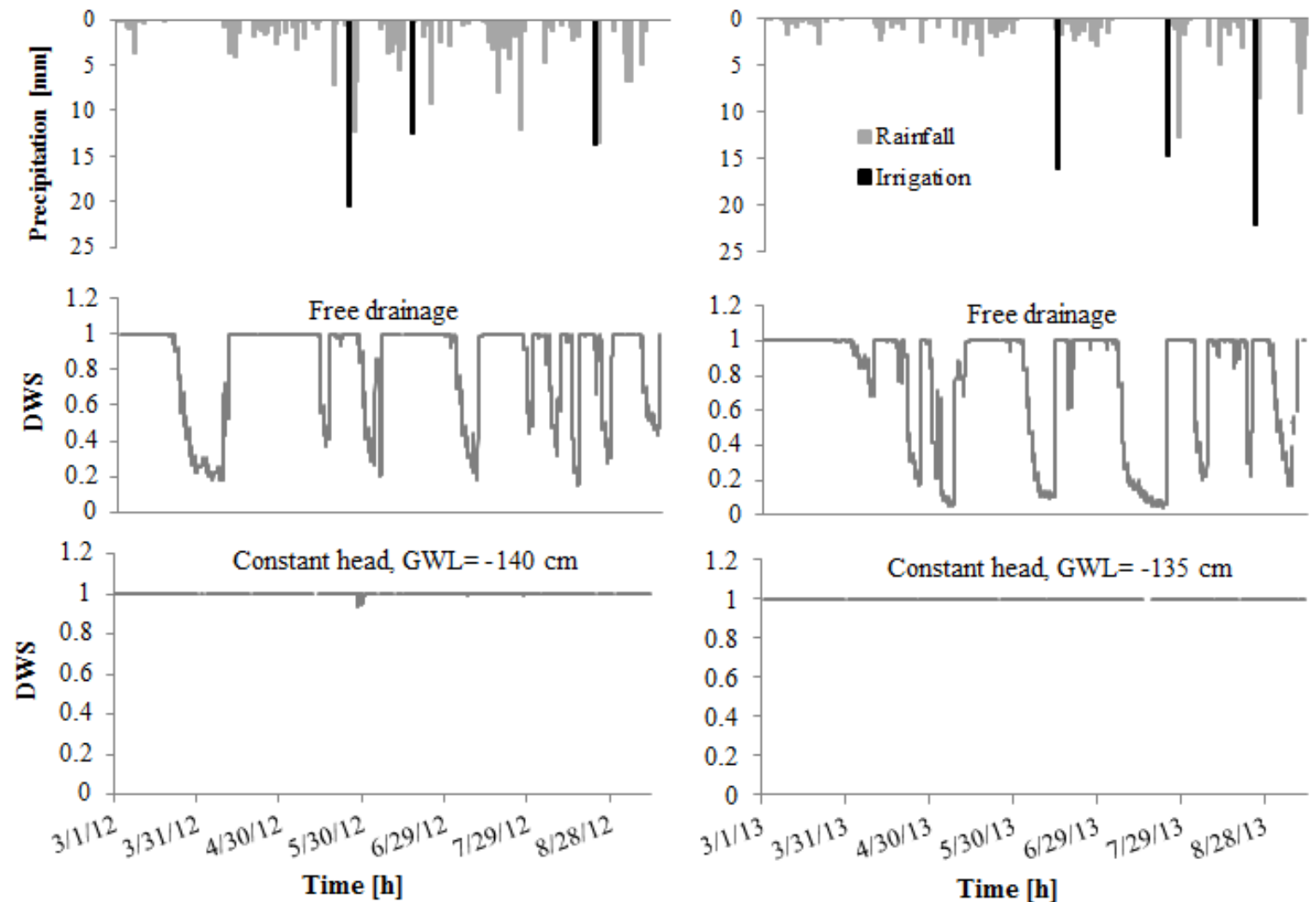

Time [h]

Time $[\mathbf{h}]$

2

3 Figure. S2: Soil water stress calculations using the uncalibrated model for free drainage and 4 constant head bottom boundary condition $(\mathrm{GWL}=-140 \mathrm{~cm})$ at the soil moisture sensor 5 location.

6

\section{2. Model Calibration}

8 The two-parameter scenario requires less parameters (one parameter for each layer) to be 9 optimized, performs performs better as compared to the uncalibrated model (Table S1, Fig. S1 and figure 5 main text) and is therefore to be preferred. 
1 Table S1. Calculated performance criteria describing the correspondence between measured 2 and simulated soil water content for each scenario for various boundary conditions.

\begin{tabular}{|c|c|c|c|c|c|c|}
\hline & $\begin{array}{l}\text { Boundary } \\
\text { condition }\end{array}$ & $\begin{array}{c}\text { Number of optimized } \\
\text { parameters }\end{array}$ & $\begin{array}{l}\text { Nodes depth } \\
\text { cm }\end{array}$ & $\mathbf{R M S E} \dagger$ & $\mathbf{C}_{\mathbf{e}} \dagger$ & $\mathbf{r}^{2}+$ \\
\hline \multirow{12}{*}{ 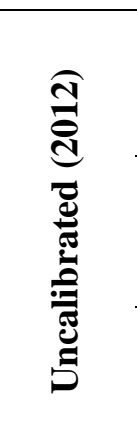 } & \multirow{4}{*}{$\begin{array}{l}\text { Constant head } \\
(-140 \mathrm{~cm})\end{array}$} & \multirow[t]{4}{*}{ paromons } & 10 & 0.029 & 0.34 & 0.58 \\
\hline & & & 20 & 0.018 & 0.44 & 0.53 \\
\hline & & & 30 & 0.016 & 0.18 & 0.38 \\
\hline & & & 40 & 0.014 & -0.03 & 0.27 \\
\hline & \multirow{4}{*}{$\begin{array}{l}\text { Constant head } \\
(-120 \mathrm{~cm})\end{array}$} & \multirow{4}{*}{0} & 10 & 0.032 & 0.2 & 0.37 \\
\hline & & & 20 & 0.039 & -1.66 & 0.26 \\
\hline & & & 30 & 0.029 & -1.65 & 0.16 \\
\hline & & & 40 & 0.023 & -1.76 & 0.08 \\
\hline & \multirow{4}{*}{ Free drainage } & \multirow{4}{*}{0} & 10 & 0.054 & -1.32 & 0.51 \\
\hline & & & 20 & 0.036 & -1.24 & 0.7 \\
\hline & & & 30 & 0.055 & -8.52 & 0.6 \\
\hline & & & 40 & 0.052 & -13.51 & 0.62 \\
\hline \multirow{36}{*}{ 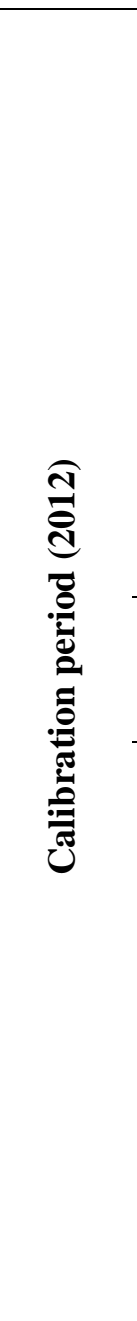 } & \multirow{16}{*}{$\begin{array}{l}\text { Constant head } \\
\qquad(-140 \mathrm{~cm})\end{array}$} & \multirow{4}{*}{6} & 10 & 0.023 & 0.56 & 0.62 \\
\hline & & & 20 & 0.016 & 0.53 & 0.74 \\
\hline & & & 30 & 0.010 & 0.67 & 0.69 \\
\hline & & & 40 & 0.008 & 0.63 & 0.64 \\
\hline & & \multirow{4}{*}{4} & 10 & 0.024 & 0.52 & 0.62 \\
\hline & & & 20 & 0.016 & 0.54 & 0.76 \\
\hline & & & 30 & 0.010 & 0.65 & 0.70 \\
\hline & & & 40 & 0.008 & 0.64 & 0.64 \\
\hline & & \multirow{4}{*}{3} & 10 & 0.026 & 0.45 & 0.62 \\
\hline & & & 20 & 0.014 & 0.65 & 0.75 \\
\hline & & & 30 & 0.010 & 0.65 & 0.70 \\
\hline & & & 40 & 0.008 & 0.63 & 0.64 \\
\hline & & \multirow{4}{*}{2} & 10 & 0.026 & 0.46 & 0.63 \\
\hline & & & 20 & 0.014 & 0.65 & 0.75 \\
\hline & & & 30 & 0.010 & 0.66 & 0.69 \\
\hline & & & 40 & 0.010 & 0.45 & 0.63 \\
\hline & \multirow{4}{*}{$\begin{array}{l}\text { Constant head } \\
(-120 \mathrm{~cm})\end{array}$} & \multirow{4}{*}{2} & 10 & 0.022 & 0.60 & 0.61 \\
\hline & & & 20 & 0.031 & -0.65 & 0.72 \\
\hline & & & 30 & 0.025 & $\begin{array}{l}-0.05 \\
-0.97\end{array}$ & 0.64 \\
\hline & & & 40 & 0.019 & -1.01 & 0.56 \\
\hline & \multirow{16}{*}{ Free drainage } & \multirow{4}{*}{6} & 10 & 0.023 & 0.57 & 0.60 \\
\hline & & & 20 & 0.018 & 0.46 & 0.71 \\
\hline & & & 30 & 0.016 & 0.19 & 0.56 \\
\hline & & & 40 & 0.011 & 0.34 & 0.50 \\
\hline & & \multirow{4}{*}{4} & 10 & 0.022 & 0.62 & 0.64 \\
\hline & & & 20 & 0.018 & 0.45 & 0.71 \\
\hline & & & 30 & 0.014 & 0.13 & 0.55 \\
\hline & & & 40 & 0.016 & -0.11 & 0.42 \\
\hline & & \multirow{4}{*}{3} & 10 & 0.032 & 0.18 & 0.54 \\
\hline & & & 20 & 0.021 & 0.29 & 0.62 \\
\hline & & & 30 & 0.027 & 0.12 & 0.50 \\
\hline & & & 40 & 0.019 & -0.95 & 0.43 \\
\hline & & & 10 & 0.028 & 0.39 & 0.51 \\
\hline & & & 20 & 0.022 & 0.31 & 0.59 \\
\hline & & 2 & 30 & 0.015 & 0.12 & 0.51 \\
\hline & & & 40 & 0.014 & -0.98 & 0.50 \\
\hline & & & 10 & 0.042 & 0.34 & 0.37 \\
\hline & & & 20 & 0.027 & 0.30 & 0.40 \\
\hline 胥 & Constant head & 2 & 30 & 0.020 & 0.24 & 0.33 \\
\hline $\bar{\nabla} \approx$ & & & 40 & 0.016 & 0.11 & 0.29 \\
\hline
\end{tabular}

$3 \uparrow \mathrm{RMSE}, \mathrm{C}_{\mathrm{e}}$ and $\mathrm{r}^{2}$ are the root-mean-square deviation, the Nash-Sutcliffe coefficient of 4 efficiency $\left(\mathrm{cm}^{3} \mathrm{~cm}^{-3}\right)$ and the coefficient of determination. 
1 3. Effect of Optimization Scenarios on Estimated Water Stress and yield 2 reduction and Irrigation Scheduling

4

\subsection{Scenario analyses on required additional irrigation}

Additional irrigation refers to the amount of irrigation that has to be added to the current irrigation to avoid water stress or that has to be subtracted from the current irrigation to avoid water loss. The impact of groundwater depth on the required additional amount was assessed using scenario analysis. The value of soil-water stress, and the number and the duration of stress periods was calculated for two growing seasons (2012 and 2013), as an indicator for the performance of the irrigation scheduling (van Dam et al., 2008). The additional required irrigation was calculated by adding an amount of water input as precipitation variable at the start time of water stress and then the model was run several times in forward mode until the calculated water stress was eliminated (by reducing or increasing amount of water supply). This procedure was repeated for each scenario and boundary condition for both years. In addition, crop yield reduction of each scenario was calculated (using Eq. 16) for both periods to show to what extent different scenarios affect soil water stress and crop yield.

\subsection{Irrigation requirement optimization}

To optimize the irrigation scheduling (timing of application), the actual water supply (all irrigation events) was deleted from the model input of the hydrological model. Secondly, the LAI simulated with the LINGRA-N for optimal conditions (no water stress) was used as a variable. Then, the hydrological model with constant bottom boundary condition was run with the new input variables to elucidate water stress without actual water supply. Then, the required irrigation was added to the precipitation at the beginning of each water stress to exclude water stress from the simulations. To simulate crop yield at the optimized condition, the new precipitation variables (rainfall and required irrigation) were used in LINGRA-N model. The optimal yield obtained using the optimized irrigation scheduling was compared to the actual (simulated and measured) yield of current irrigation management practices. Table 4. Total duration, number and extent of water stress for different boundary conditions and scenarios (from 1 Mar. to 12 Sep.). Total rainfall and irrigation amount were 398.2 and $64.5 \mathrm{~mm}$ in 2012 and 413.2 and $85.4 \mathrm{~mm}$ in 2013 respectively. Number between 
1 parentheses represents the duration of first water stress event due to light-radiation and

2 temperature limitations.

\section{$3 \quad 3.3$ Irrigation scheduling scheme}

\section{$4 \quad 3.3 .1$ Scenario analyses}

5 Calculated cumulative actual fluxes across the bottom of the soil profile were $-15.4 \mathrm{~mm}$ and $6 \quad 63.3 \mathrm{~mm}$ (outflow and upward-inflow respectively) (Figs. S3, S4, S6). There was a 7 significant effect of the bottom boundary condition on the calculated water stress. A free 8 drainage condition (calibrated and uncalibrated) resulted in a larger number, longer duration 9 of stress conditions (Fig. 6 main text and Table S2) and overestimated water stress due to 10 excessive recharge to the groundwater (more than148 mm). When the ground water level 11 was $-140 \mathrm{~cm}$ the outflow of the bottom flux decrease from six-optimized parameters 12 scenario $(4.6 \mathrm{~mm})$ to two- parameters scenario $(15.4 \mathrm{~mm})$ in calibration period. While 13 upward flow increased with increasing number of optimized parameters in validation period 14 (63.3 to $76.9 \mathrm{~mm}$ ). But these inflow did not meet the crop water requirement. Overall, to 15 overcome the water stress effects on crop yield, additional required irrigation should be 16 supplied for different optimization scenarios and boundary conditions (Table S2). During 17 water stress, yield reduction would be in range of 0 to $33 \%$ for different optimization 18 scenarios (Fig. S5 and Table 4 main text).

\section{$19 \quad 3.3 .2$ Irrigation requirement optimization}

20 Irrigation volume effects on soil water fluxes. In no irrigation scenario of calibrated model 21 (constant head $-140 \mathrm{~cm}$ ) the inflow fluxes were greater than current and guided irrigation 22 scenarios (Fig. S6 and Fig. 8 main text). 
Table S2. Comparison of optimized irrigation schedule with farmer's conventional irrigation schedule.

\begin{tabular}{|c|c|c|c|c|c|c|c|c|}
\hline & Boundary condition & $\begin{array}{l}\text { Number of } \\
\text { parameters } \\
\text { optimized }\end{array}$ & $\begin{array}{c}\text { Number of } \\
\text { water stress } \\
\text { periods }\end{array}$ & $\begin{array}{c}\text { Total } \\
\text { Duration } \\
\text { of water } \\
\text { stress }\end{array}$ & $\begin{array}{c}\text { Degree of } \\
\text { water } \\
\text { stress }\end{array}$ & $\begin{array}{l}\text { Profile } \\
\text { bottom } \\
\text { flux }\end{array}$ & $\begin{array}{l}\text { Additional } \\
\text { required } \\
\text { irrigation }\end{array}$ & $\begin{array}{l}\text { Yield } \\
\text { reduction }\end{array}$ \\
\hline \multirow{8}{*}{ 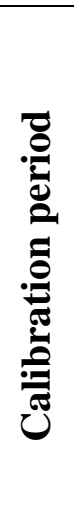 } & & & & $\mathrm{h}$ & & \multicolumn{2}{|r|}{$\mathrm{mm}$} & $\%$ \\
\hline & Constant head $(-140 \mathrm{~cm})$ uncalibrated & 0 & 0 & 0 & $\geq 1$ & -8.1 & 0 & 0 \\
\hline & Free drainage uncalibrated & 0 & 9 & $1369(436)$ & 0.20 & -310.1 & 120 & 28 \\
\hline & Free drainage & 2 & 7 & $867(345)$ & 0.37 & -167.7 & 60 & 18 \\
\hline & Constant head $(-120 \mathrm{~cm})$ & 2 & 0 & 0 & $\geq 1$ & 71.9 & 0 & 0 \\
\hline & Constant head $(-140 \mathrm{~cm})$ & 2 & 7 & $671(328)$ & 0.65 & -15.4 & 50 & 16 \\
\hline & Constant head $(-140 \mathrm{~cm})$ & 4 & 4 & $524(277)$ & 0.65 & -1 & 50 & 13 \\
\hline & Constant head $(-140 \mathrm{~cm})$ & 6 & 5 & $540(276)$ & 0.66 & -4.6 & 45 & 13 \\
\hline \multirow{7}{*}{ 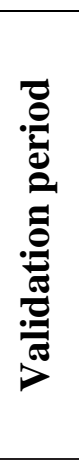 } & $\begin{array}{l}\text { Constant head }(-135 \mathrm{~cm}) \\
\text { uncalibrated }\end{array}$ & & 0 & 0 & $\geq 1$ & 105.5 & 0 & 0 \\
\hline & Free drainage uncalibrated & 0 & 11 & 1371 & 0.05 & -222.9 & 120 & 33 \\
\hline & Free drainage & 2 & 7 & 1093 & 0.10 & -148.7 & 70 & 23 \\
\hline & Constant head $(-120 \mathrm{~cm})$ & 2 & 1 & 20 & 0.85 & 64.4 & 5 & 0 \\
\hline & Constant head $(-135 \mathrm{~cm})$ & 2 & 5 & 675 & 0.65 & 63.3 & 30 & 13 \\
\hline & Constant head $(-135 \mathrm{~cm})$ & 4 & 4 & 598 & 0.65 & 76.6 & 20 & 11 \\
\hline & Constant head $(135 \mathrm{~cm})$ & 6 & 3 & 579 & 0.65 & 76.9 & 20 & 11 \\
\hline
\end{tabular}



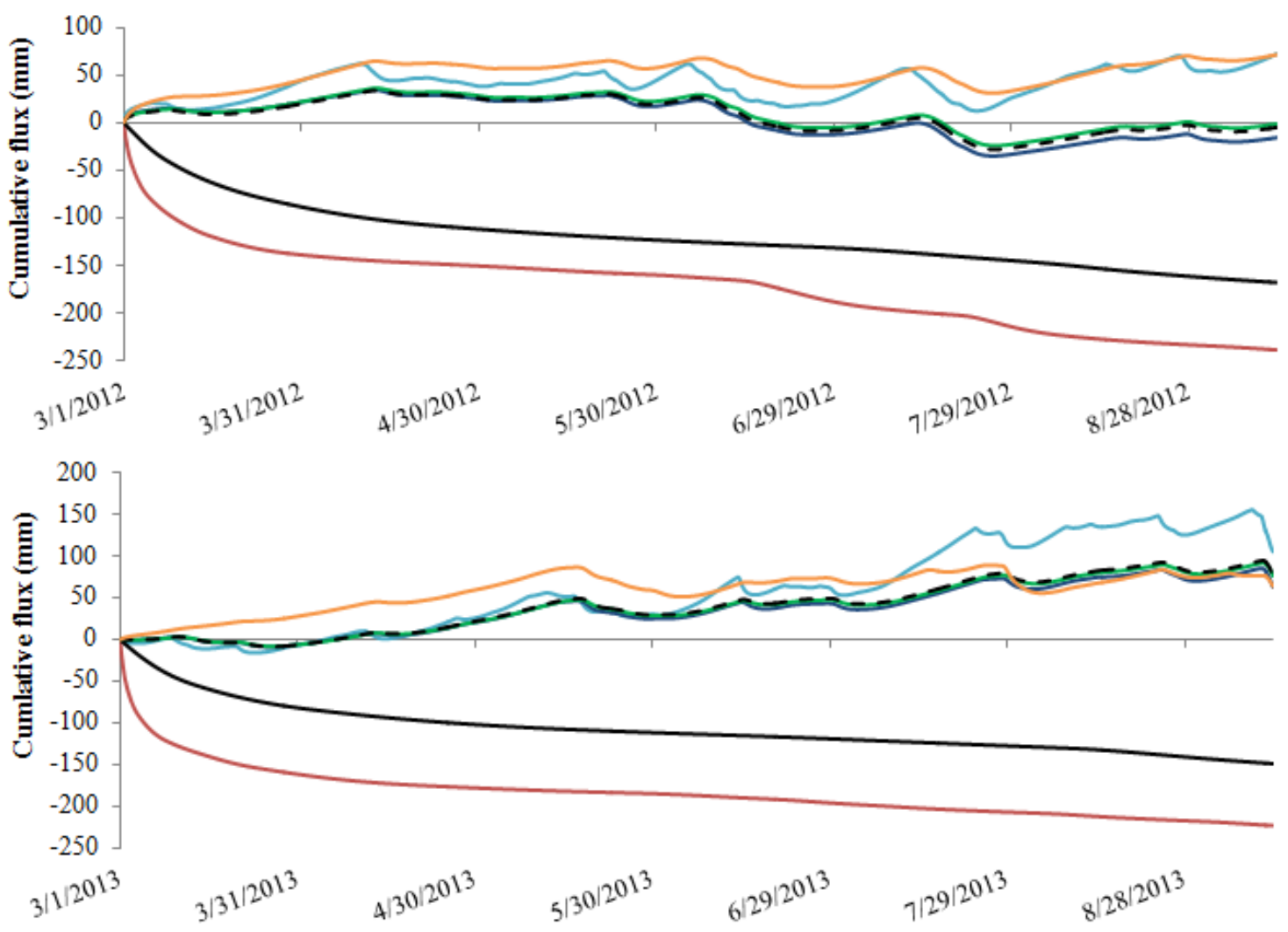

Time [h]

Constant head uncalibrated
Free drainage, 2 parameters optimized
Constant head, 4 parameters optim ized
Constant head, $-120 \mathrm{~cm}, 2$ parameters optim ized

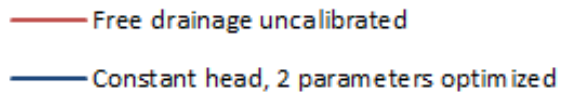

- - constant head, 6 parameters opt imized

4 Figure S3. Cumulative fluxes of different boundary condition and parameter scenarios for 5 calibration and validation periods. 

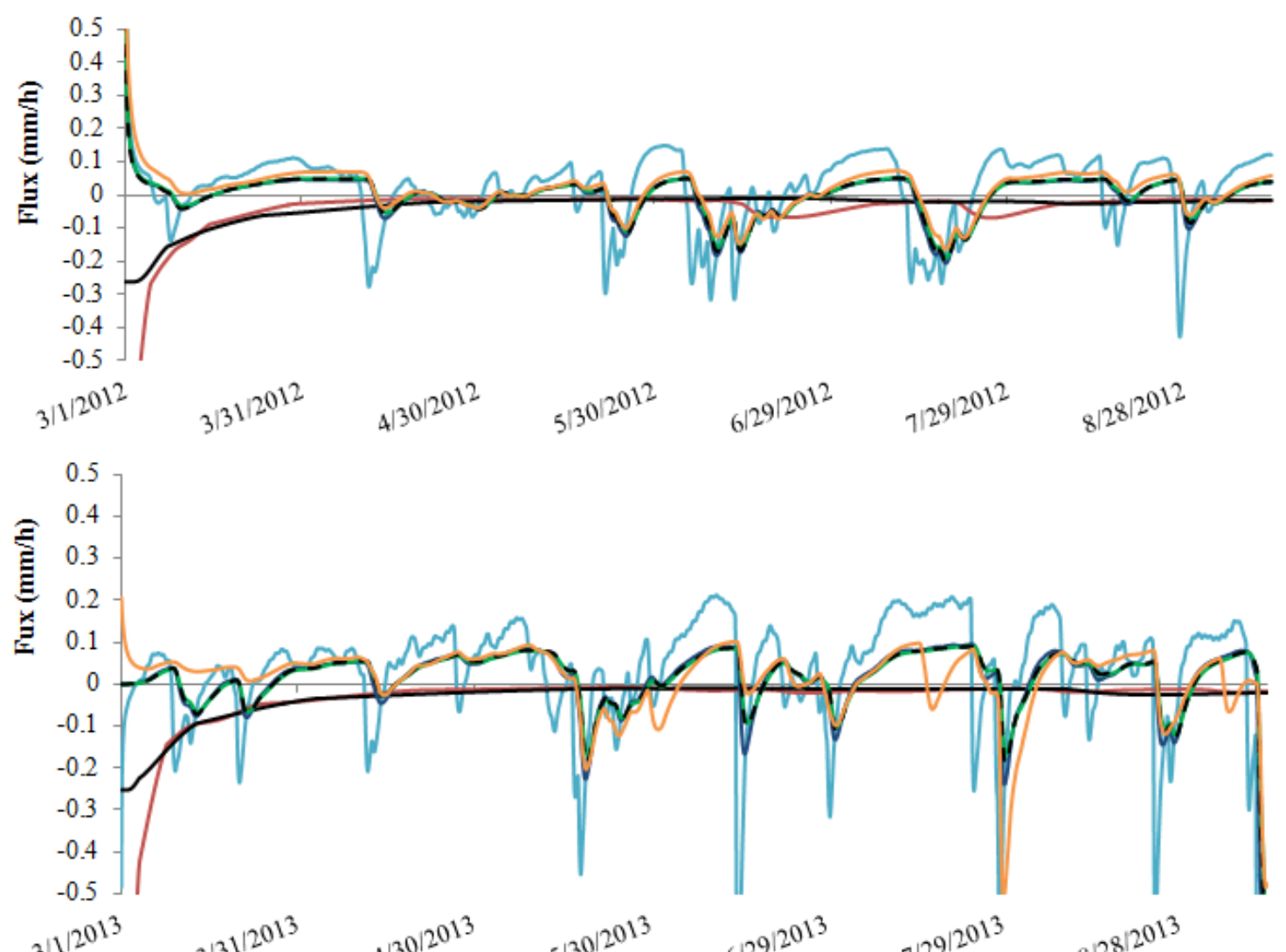

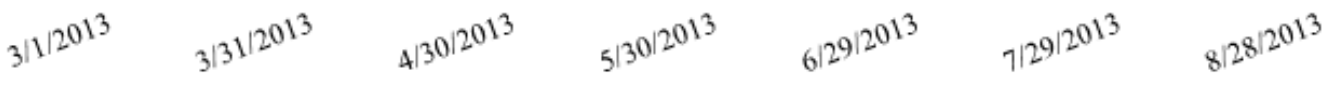

Time [h]

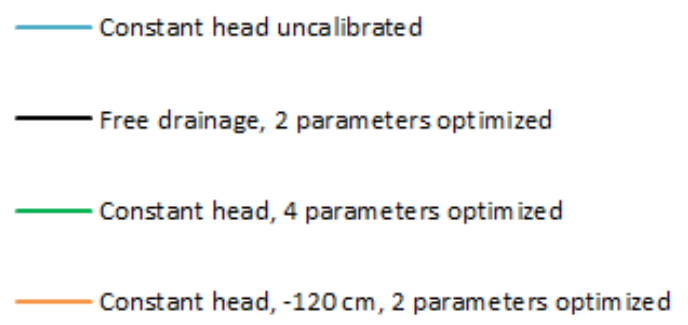

- Free drainage uncalibrated

Constant head, 2 parameters optim ized

- - constant head, 6 parameters optimized

Constant head, $-120 \mathrm{~cm}, 2$ parameters optim ized

4 Figure S4. Actual fluxes of different boundary condition and parameter scenarios for 5 calibration and validation periods. 

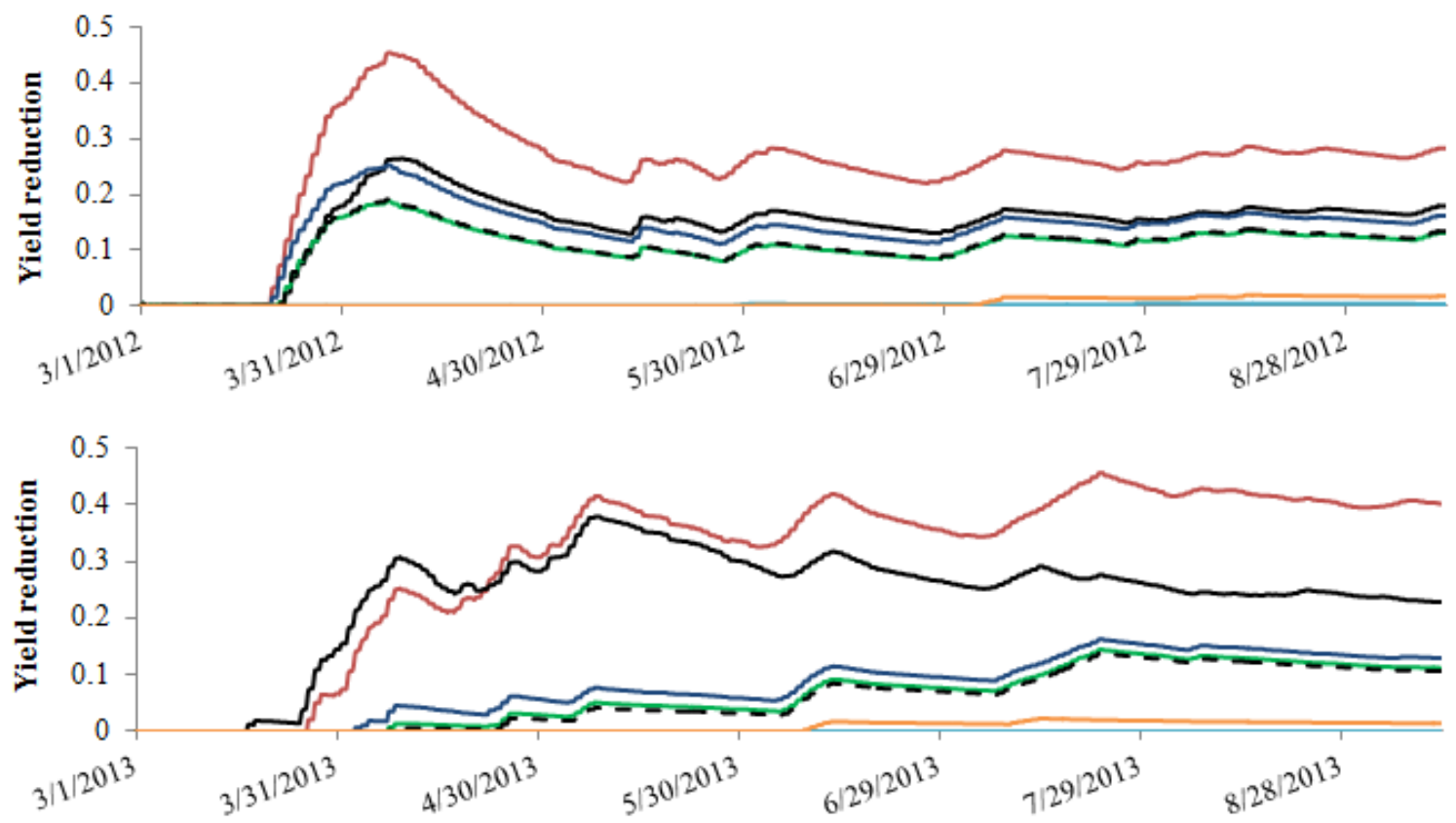

Time $[\mathrm{h}]$
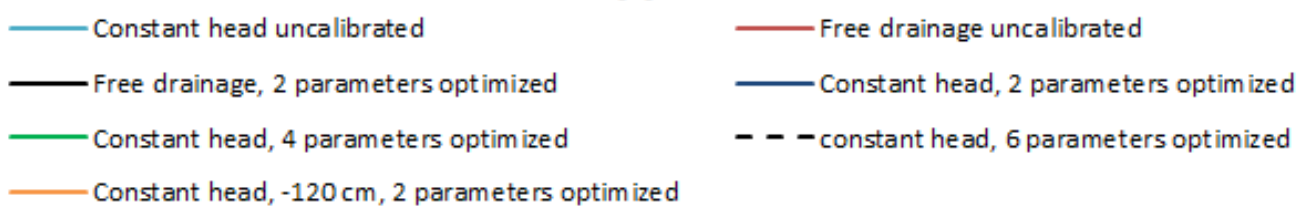

- - constant head, 6 parameters opt imized

1

2

3 Figure S5. Yield reduction of various scenarios and bottom boundary conditions in 2012 4 and 2013 (Eq. 16). 

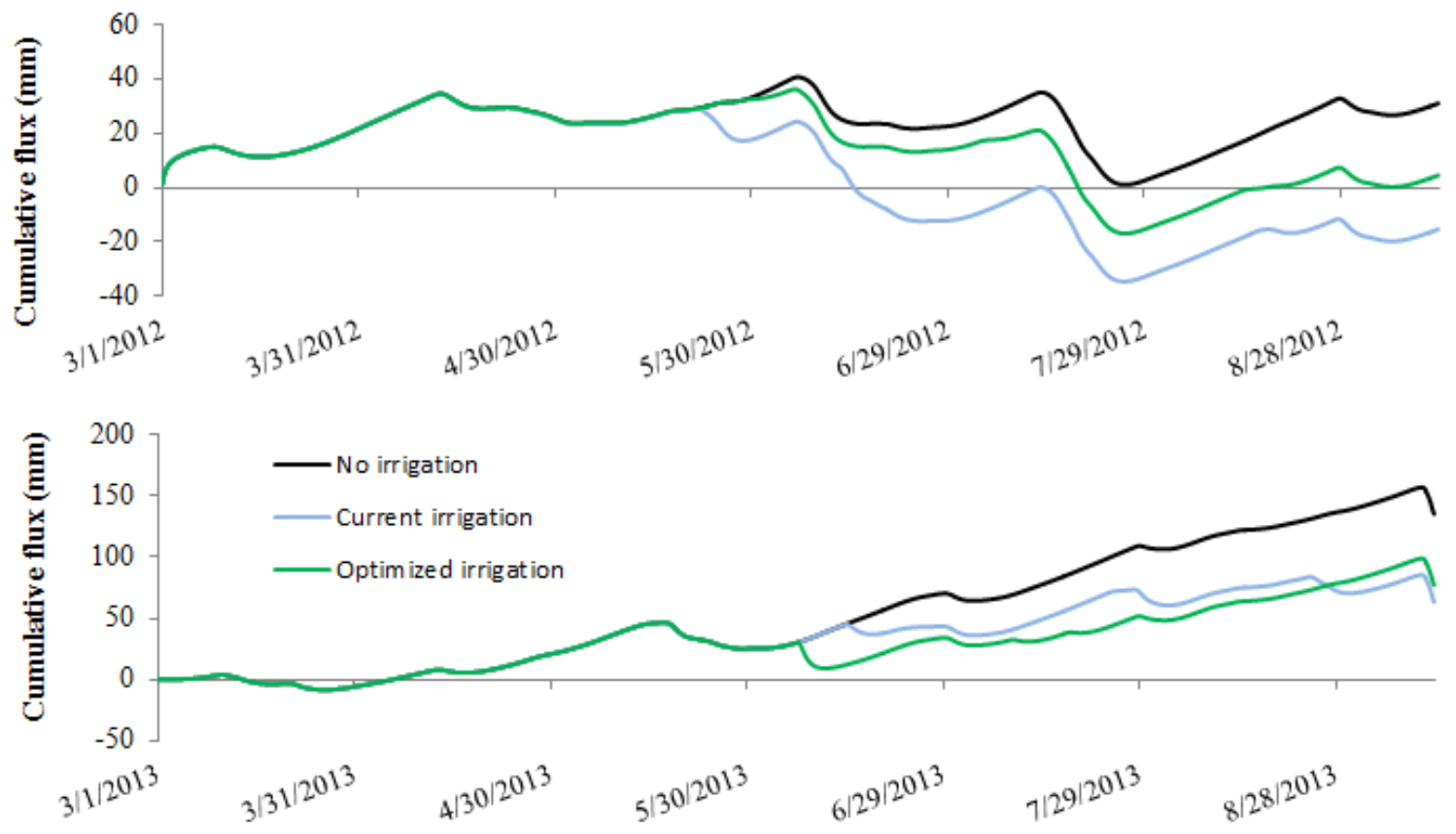

Time [h]

2

3 Figure S6. Cumulative flux of farmer's conventional irrigation (current irrigation), without 4 irrigation and optimized irrigation scheme (guided irrigation) for calibration and validation 5 periods. 


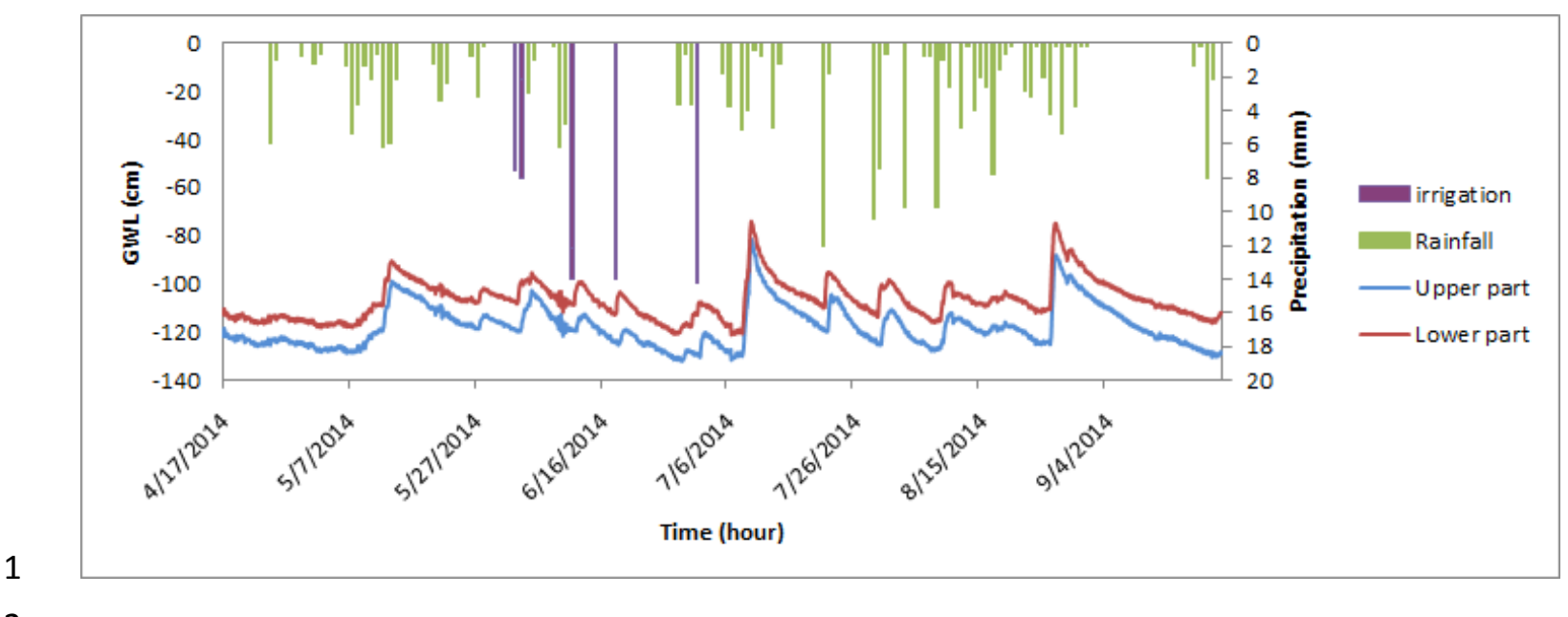

2

3 Figure S7. Ground water fluctuation in new field without drainage system in 2014. 